ORIGINAL ARTICLE

\title{
PENINGKATAN PENGETAHUAN GURU TENTANG P3K MELALUI PROMOSI KESEHATAN DI SMK KAL 1 SURABAYA
}

\author{
Nisha Dharmayanti Rinarto ${ }^{1^{*}}$, Dwi Priyantini ${ }^{2}$, Annisa Nurayu Fitriastuti ${ }^{3}$ \\ ${ }^{1,2,3}$ Program Studi S1 Keperawatan, Sekolah Tinggi Ilmu Kesehatan Universitas Hang Tuah Surabaya, Indonesia \\ *Correspondent Author: nishadharmayanti@stikeshangtuah-sby.ac.id/nishadr.shtsby@gmail.com
}

\section{ARTICLE INFO}

Article history:

Received 23 January 2019

Received in revised form

February 2019

Accepted 4 February 2019

\section{Keywords:}

Health Promotion,

First Aid,

School.

\section{Kata Kunci:}

PromosiKesehatan,

P3K,

Sekolah.

\section{ABSTRACT}

Health promotion is an effort planned to influence other people, whether individuals, groups or communities, so that they do what is expected by health promotion actors. Health promotion of $\mathrm{P} 3 \mathrm{~K}$ in schools has an effect on the level of knowledge that teachers have about P3K on emergencies. This study aims to see the effect of health promotion on increasing teacher knowledge about first aid at Surabaya KAL-1 Vocational School. Sampling technique with Simple Random Sampling, a total sample of 39 respondents. The research method is Pre Experimental with the One Group Pretest-Posttest approach. Data collection using questionnaires. Data analysis techniques using the Wilcoxon Signed Rank Test. The results of the study showed that the teacher's knowledge before being given a health promotion with an average value of 1.38 and after being given a health promotion obtained an average value of 2.54. The results of statistical tests obtained the results of Asymp. Sig 0.001> $\alpha 0.05$, which means that there are significant differences. Further analysis found that there was an effect of health promotion on the level of teacher knowledge, so it was hoped that the school would propose to the relevant UPTD for the provision of first aid training in schools.

\section{ABSTRAK}

Promosi kesehatan merupakan upaya yang direncanakan untuk mempengaruhi orang lain, baik individu, kelompok, atau masyarakat, sehingga mereka melakukan apa yang diharapkan oleh pelaku promosi kesehatan. Promosi kesehatan tentang P3K disekolah berpengaruh terhadap tingkat pengetahuan yang dimiliki oleh guru tentang P3K pada kegawatdaruratan. Penelitian ini bertujuan untuk melihat pengaruh promosi kesehatan terhadap peningkatan pengetahuan guru tentang P3K di SMK KAL-1 Surabaya. Tehnik sampling dengan Simple Random Sampling, jumlah sampel 39 responden. Metode penelitian adalah Pre Eksperimental dengan pendekatan One Grup PretesPostest. Pengumpulan data menggunakankuesioner. Teknik analisis data menggunakan Wilcoxon Signed Rank Test. Hasil penelitian menunjukkan pengetahuan guru sebelum diberikan promosi kesehatan dengan nilai rata-rata 1,38 dan setelah diberikan promosi kesehatan didapat nilai rata-rata 2,54. Hasil uji statistik diperoleh hasil Asymp.Sig 0,001 $>\alpha$ 0,05 yang berarti terjadi perbedaan yang bermakna. Analisis lebih lanjut didapatkan ada pengaruh promosi kesehatan terhadap tingkat pengetahuan guru, dengan demikian diharapkan agar sekolah mengusulkan kepada UPTD terkait untuk pengadaan pelatihan P3K di sekolah.

@ 2019 Medical and Health Science Journal. All rights reserved 


\section{PENDAHULUAN}

Kejadian gawat darurat dapat diartikan sebagai keadaan dimana seseorang memerlukan pertolongan segera karena apabila tidak mendapat pertolongan dengan segera maka dapat mengancam jiwanya atau menimbulkan kecacatan permanen. Keadaan gawat darurat yang sering terjadi di masyarakat antara lain keadaan seseorang yang mengalami henti nafas dan henti jantung, tidak sadarkan diri, kecelakaan, cedera misalnya patah tulang, pendarahan, kasus stroke dan kejang, keracunan dan korban bencana (Norman, 2006).

Menurut survey yang dilakukan di tempat penelitian angka kejadian cedera pada lingkungan sekolah sering terjadi. Terutama saat praktik kompetensi keahlian siswa, terutama bidang keahlian Teknik Mesin dan Teknik Listrik lebih tinggi resiko cedera yang akan dialami. Selain itu cedera saat berolahraga juga sering dijumpai, misalnya dengan kaki terkilir setelah bermain futsal. Disamping itu pengetahuan guru tentang P3K pada siswa masih dikatakan kurang hal ini yang menjadi dasar pengambilan penelitian di tempat ini.

Hasil studi pendahuluan melalui wawancara dengan kepala UKS di SMK KAL-1 Surabaya dalam organisasi UKS yang ada di sekolah yang bertanggung jawab hanyalah Kepala UKS yang dibantu dengan kader kesehatan yaitu salah satu siswa dalam setahun. Ketika terjadi kecelakaan kerja saat praktikum misalnya luka sobek pada jari yang terkena gergaji atau grenda maka siswa akan dibawa di UKS dan ditangani langsung oleh Kepala UKS yang siaga diruangan. Apabila kepala UKS tidak mampu untuk menangani maka siswa dirujuk ke RS terdekat. Pada saat praktikum siswa bidang Teknik seperti kegiatan mengelas, siswa sering mengeluh mata merah karena terlalu lama terpapar sinar las. Selain itu, terkadang terjadi luka bakar ringan pada siswa yang terkena soldier saat praktikum. Beberapa siswa tersebut dibawa temantemannya ke ruang UKS dan diberikan P3K oleh kepala UKS.

UKS di SMK KAL-1 berada dalam naungan UPTD Puskesmas Krembangan Selatan akan tetapi dari hasil wawancara dengan kepala UKS menyebutkan bahwa selama ini belum ada promosi kesehatan terkait P3K pada siswa di sekolah dan menurut Kepala UKS, guru pendidik belum mengetahui tentang P3K pada siswa sehingga apabila terjadi kecelakan saat praktik maupun adanya siswa yang pingsan atau sakit akut hanya mengandalkan Kepala UKS saja. Alat P3K di ruang UKS sendiri masih belum lengkap dan ruangan yang terlalu kecil untuk jumlah siswa yang cukup banyak menjadi masalah dalam UKS tersebut.

P3K adalah perawatan yang segera diberikan pada orang yang cedera atau mendadak sakit, namun tidak dapat menggantikan perawatan medis yang sebenarnya, karena hanya memberi bantuan sementara sampai mendapatkan perawatan medis yang kompeten jika perlu atau sampai pulih tanpa perawatan medis. P3K yang diterapkan secara tepat dapat memberi perbedaan antara hidup dan mati, antara pemulihan yang cepat dan rawat inap di rumah sakit yang lama, atau antara kecacatan temporer dan kecacatan permanen. P3K lebih banyak melakukan tindakan untuk orang lain; P3K juga termasuk melakukan tindakan yang dapat dilakukan orang dalam suatu kedaruratan untuk diri mereka sendiri (Thygerson, 2011)

Kecelakaan atau kedaruratan dapat saja terjadi secara tidak disangka-sangka (Junaidi, 2011). Kecelakaan dapat terjadi di rumah, perjalanan, tempat kerja, sekolah, dan tempat lainnya. Sebagai akibat dari kecelakaan korban dapat mengalami cedera ringan atau berat, pingsan, cacat seumur hidup atau bahkan sampai meninggal dunia. Bagi korban yang meninggal dunia tentu tidak memerlukan suatu pertolongan yang cepat, tetapi bagi korban kecelakaan yang masih hidup 
memerlukan suatu pertolongan yang cepat dan tepat agar korban dapat terhindar dari bahaya maut. Ilmu P3K pada kecelakaan sebaiknya dimiliki oleh semua orang. Tujuannya adalah mencegah maut dan mempertahankan hidup, mencegah penurunan kondisi badan atau cacat(Yuda, Tamara, \& Agina, 2015).

Penyebab terjadinya cedera meliputi penyebab yang disengaja (intentional injury), penyebab yang tidak disengaja (unintentional injury) dan penyebab yang tidak bisa ditentukan (undeterminated) (Badan Penelitian dan Pengembangan Kesehatan, 2013)

Prevalensi cedera secara nasional adalah 8,2\% (berdasarkan pengakuan responden, untuk berbagai penyebab cedera). Penyebab cedera terbanyak yaitu jatuh $(40,9 \%)$ dan kecelakaan sepeda motor $(40,6 \%)$, selanjutnya penyebab cedera karena terkena benda tajam/tumpul (7,3\%), transportasi darat lain $(7,1 \%)$ dan kejatuhan $(2,5 \%)$. Di Jawa Timur sendiri prevalensi angka cedera $(9,3 \%)$ dengan penyebab cedera tertinggi diakibatkan Jatuh $(43,2 \%)$ urutan kedua disebabkan sepeda motor $(37,9 \%)$ dan selanjutnya disebabkan transportasi darat $(8,5 \%)$, Benda tajam/tumpul $(7,2 \%)$. Prevalensi cedera tertinggi menurut karakteristik umur berada di usia 15-24 tahun $(11,7 \%)$. Sedangkan untuk jenis cedera di Indonesia didominasi oleh luka lecet/memar sebesar 70,9\% dan terbanyak kedua adalah terkilir $(27,5 \%)$, selanjutnya menduduki urutan ketiga jenis cedera dengan luka robek $(23,2 \%)$, Patah Tulang (5,8\%). Proporsi jenis cedera di provinsi Jawa Timur tertinggi adalah Lecet/Memar $(68,0 \%)$, kedua Terkilir (27,3\%), ketiga Luka robek (22,7\%), Patah Tulang (6,0\%). Angka kejadian cedera di sekolah secara nasional adalah $(5,4 \%)$, dan proporsi cedera di sekolah di Jawa Timur $(6,0 \%)$ dan disebabkan oleh olahraga (3,5\%) (Badan Penelitian dan Pengembangan Kesehatan, 2013).

Guru selaku penanggung jawab saat praktikum memiliki peran yang sangat penting saat melakukan P3K pada siswa yang mengalami cedera tersebut. Dengan pemberian P3K yang cepat dan tepat pada siswa yang mengalami cedera akan cepat tertolong dan dengan adanya promosi kesehatan akan memberikan tambahan pengetahuan guru tentang P3K kegawatdaruratan guna memberikan pertolongan yang cepat dan tepat agar kondisi yang mengancam jiwa segera teratasi dengan baik. Guru sebaiknya menguasai P3K di sekolah. Penguasaan tindakan dipengaruhi oleh beberapa hal salah satunya adalah pengetahuan(Gunarsa, 2008). Pengetahuan dapat diberikan dengan melakukan promosi kesehatan tentang $\mathrm{P} 3 \mathrm{~K}$, dimana program kesehatan yang dirancang secara efektif untuk membawa perubahan (perbaikan), baik di dalam masyarakat sendiri, maupun dalam organisasi dan lingkungannya.

\section{METODE PENELITIAN}

Penelitian ini menggunakan desain Pre Eksperimental dengan pendekatan One Grup Pretes Postest untuk mengungkapkan hubungan sebab akibat dengan cara melibatkan satu kelompok subjek. Populasi dalam penelitian ini adalah semua guru di SMK KAL-1 Surabaya berjumlah 44 orang dengan sampel yang memenuhi kriteria inklusi sebesar 39 orang.Teknik sampling yang digunakan yaitu probability sampling dengan cara simple random sampling.

Pengambilan data dengan menggunakan lembar kuesioner yang dibuat sendiri oleh peneliti dan telah di uji validitas dan reabilitasnay. Analisis data menggunakan Wilcoxon Signed Rank Test untuk melihat apakah terdapat hubungan antara tingkat pengetahuan guru sebelum dan sesudah diberikannya promosi kesehatan. Hipotesa diterima jika nilai $\rho \leq 0,05$. 
HASIL DAN PEMBAHASAN

\section{Data Umum}

Tabel 1. Karakteristik Guru Berdasarkan Usia di SMK KAL-1 Surabaya, tanggal 15-16 Maret 2017

\begin{tabular}{ccc}
\multicolumn{3}{c}{$(\mathrm{n}=39)$} \\
\hline Usia & $\mathbf{F}$ & $\mathbf{\%}$ \\
\hline$<40$ Tahun & 17 & 43,6 \\
$40-50$ & 16 & 41,0 \\
Tahun & 6 & 15,4 \\
$51-61$ & & \\
Tahun & & \\
\hline Total & $\mathbf{3 9}$ & $\mathbf{1 0 0}$ \\
\hline
\end{tabular}

Tabel 2. Karakteristik Guru Berdasarkan Jenis Kelamin Di SMK KAL-1 Surabaya, tanggal 15-16 Maret $2017(n=39)$

\begin{tabular}{ccc}
\hline Jenis & f & \% \\
Kelamin & 22 & 56,4 \\
Perempuan & 17 & 43,6 \\
Laki - laki & $\mathbf{3 9}$ & $\mathbf{1 0 0}$ \\
\hline Total &
\end{tabular}

Tabel 3. Karakteristik Guru Berdasarkan Tingkat Pendidikan Di SMK KAL-1 Surabaya, tanggal 1516 Maret $2017(\mathrm{n}=39)$

\begin{tabular}{ccc}
\hline Tk. Pendidikan & $\mathbf{f}$ & \% \\
\hline D3 Sederajat & 8 & 20,5 \\
Lulus Sarjana & 26 & 66,7 \\
Lulus Magister & 5 & 12,8 \\
\hline Total & $\mathbf{3 9}$ & $\mathbf{1 0 0}$ \\
\hline
\end{tabular}

Tabel 4. Karakteristik Guru Berdasarkan Pekerjaan Di SMKKAL-1 Surabaya, tanggal 1516 Maret $2017(n=39)$

\begin{tabular}{ccc}
\hline Pekerjaan & f & \% \\
\hline TNI-AL & 4 & 10,3 \\
Swasta & 20 & 51,3 \\
Honorer / & 15 & 38,5 \\
Lain-lain & & \\
\hline Total & $\mathbf{3 9}$ & $\mathbf{1 0 0}$ \\
\hline
\end{tabular}

Tabel 5. Karakteristik Guru Berdasarkan Lama Bekerja Di SMK KAL-1 Surabaya, tanggal 15-16 Maret $2017(n=39)$

\begin{tabular}{ccc}
\hline Lama Bekerja & $\mathbf{f}$ & $\boldsymbol{\%}$ \\
\hline$>2$ tahun & 39 & 100 \\
\hline Total & $\mathbf{3 9}$ & $\mathbf{1 0 0}$ \\
\hline
\end{tabular}

Tabel 6. Karakteristik Guru Berdasarkan Keikutsertaan dalam Pelatihan P3K Di SMK KAL-1 Surabaya, tanggal 15-16 Maret 2017 $(\mathrm{n}=39)$

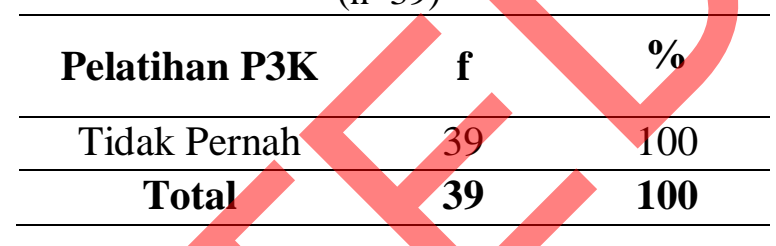

\section{Data Khusus}

Tabel 8. Tingkat Pengetahuan Guru Sebelum Pemberian Promosi Kesehatan Tentang P3K Pada Siswa di SMK KAL-1 Surabaya, tanggal 15-16 Maret $2017(n=39)$

\begin{tabular}{ccc}
\hline Kategori & f & \% \\
\hline Cukup & 11 & 28,2 \\
Kurang & 28 & 71,8 \\
\hline Total & $\mathbf{3 9}$ & $\mathbf{1 0 0}$ \\
\hline
\end{tabular}

Tabel 8 menunjukkan bahwa dari 39 guru SMK KAL-1 Surabaya terdapat 11 orang $(28,2 \%)$ memiliki pengetahuan yang cukup, 28 orang $(71,8 \%)$ memiliki pengetahuan yang kurang.

Tabel 9. Tingkat Pengetahuan Guru Sesudah Pemberian Promosi Kesehatan Tentang P3K Pada Siswa di SMK KAL-1 Surabaya, tanggal 15-16 Maret $2017(n=39)$

\begin{tabular}{ccc}
\hline Kategori & $\mathbf{f}$ & $\mathbf{\%}$ \\
\hline Baik & 21 & 53,8 \\
Cukup & 18 & 46,2 \\
\hline Total & $\mathbf{3 9}$ & $\mathbf{1 0 0}$ \\
\hline
\end{tabular}

Tabel 9 menunjukkan bahwa dari 39 guru SMK KAL-1 Surabaya sebanyak 21 orang $(53,8 \%)$ memiliki pengetahuan yang baik, 18 orang $(40,2 \%)$ memiliki pengetahuan yang cukup. 
Tabel 10. Pengaruh Promosi Kesehatan Sebelum dan Sesudah Dilakukan Promosi kesehatan Tentang P3K Kegawatdaruratan Pada Siswa Di Sekolah Terhadap Tingkat Pengetahuan Guru di SMK KAL-1 Surabaya

\begin{tabular}{cccccccc} 
& \multirow{2}{*}{} & Mean & $\begin{array}{c}\text { Std } \\
\text { Dev }\end{array}$ & Min & Max & \multicolumn{2}{c}{ Precentiles } \\
\hline Pre & 39 & 1,38 & 5,9 & 1 & 3 & 1,00 & 50th (Med) \\
\hline Post & 39 & 2,54 &, 590 & 2 & 3 & 2,00 & 3,00 \\
\hline
\end{tabular}

Tabel 10 menunjukkan bahwa dari uji statistik menggunakan Wilcoxon Sign Test diperoleh nilai $p$ value $=0,001(\alpha \leq 0,05)$. Hal ini membuktikan bahwa ada pengaruh yang signifikan antara Pemberian promosi kesehatan terhadap tingkat pengetahuan guru tentang P3K kegawatdaruratan pada siswa di SMK KAL-1 Surabaya.

\section{Pengetahuan Guru tentang P3K Pada Siswa di SMK KAL-1 Surabaya Sebelum Diberikan Promosi Kesehatan}

Hasil pretest menunjukkan bahwa sebelum diberikan promosi kesehatan tentang pengetahuan guru P3K pada siswa di sekolah SMK KAL-1 Surabaya sebanyak 28 guru $(71,8 \%)$ memiliki pengetahuan yang kurang dan pengetahuan cukup sebanyak 11 responden $(28,2 \%)$.

Hal ini menunjukkan bahwa guru di SMK KAL-1 kurang mengetahui dasar P3K yang harus diperhatikan saat melakukan P3K, hal-hal pokok yang harus diketahui oleh penolong, dampak yang timbul pada korban, sumber daya yang dapat dipergunakan saat menolong dan teknik P3K dalam evakuasi dan memindahkan korban. Hal ini disebabkan karena kurangnya informasi yang di dapat baik melalui media masa (televisi, koran, atau internet) dan tidak pernah mendapatkan pendidikan kesehatan dari UPTD terkait P3K pada siswa di sekolah.

Pengetahuan Guru tentang P3K di SMK KAL1 Surabaya Setelah Diberikan Promosi Kesehatan
Hasil posttest menunjukkan bahwa setelah diberikan promosi kesehatan tentang pengetahuan P3K di sekolah SMK KAL-1 Surabaya sebanyak 21 guru $(53,8 \%)$ mempunyai pengetahuan yang baik (76\%-100\%), dikarenakan memiliki kesadaraan, minat dan antusias yang baik terhadap materi promosi kesehatan. Sebanyak 18 guru (46,2\%) mempunyai pengetahuan yang cukup dikarenakan kurangnya minat terhadap promosi kesehatan.

Tujuan diberikan promosi kesehatan tentang P3K di sekolah adalah meningkatkan pengetahuan guru tentang pengertian $\mathrm{P} 3 \mathrm{~K}$ hingga bagaimana teknik P3K dalam evakuasi korban dan pertolongan yang cepat, efesien dan aman bagi penolong. Sehingga, guru maupun petugas UKS dapat memberikan pertolongan dengan tepat dan sesuai sehingga dapat mencegah keparahan yang terjadi atau hal-hal yang tidak diinginkan.

Pengaruh Promosi Kesehatan tentang P3K terhadap Tingkat Pengetahuan Guru Tentang P3K Di SMK KAL-1 Surabaya

Hasil penelitian ini menunjukkan bahwa rata-rata pengetahuan yang dimiliki guru SMK KAL-1 sebelum diberikannya intervensi adalah 1,38 dengan standart deviasi 590. Sedangkan hasil yang diperoleh setelah diberikannya intervensi rata-rata pengetahuan guru adalah 2,54 dengan standart deviasi 505. Perbedaan nilai mean antara pretest dan posttest adalah 18. 00. Hasil uji Wilcoxon Signed Rank Test didapatkan nilai Asymp. Sig. (2-tailed) =0. 01 sehingga dapat dinyatakan bahwa terdapat peningkatan pengetahuan yang bermakna setelah dilakukan promosi kesehatan. Peningkatan pengetahuan tentang P3K dari tingkat kurang ke tingkat cukup maupun ke tingkat baik disebabkan karena pemberian promosi kesehatan.

Guru yang memiliki tingkat pengetahuan yang cukup disebabkan karena minimnya informasi tentang pentingnya P3K pada siswa di sekolah (Rizqiani, 2016). Setelah dilakukan penyuluhan 
dengan metode ceramah melalui leaflet dan power point hampir semua guru memahami tentang P3K di sekolah pada siswa. Menurut Nurhanifah (2017), melalui promosi kesehatan salah satunya dengan metode ceramah atau penyuluhan yang diberikan dapat membuat guru mengerti dan memahami apa yang telah disampaikan sesuai indikator.

Promosi kesehatan tentang P3K di sekolah yang diberikan kepada guru adalah salah satu upaya untuk meningkatkan pengetahuan guru. Peningkatan skor sebelum dan sesudah diberikannya promosi kesehatan karena ketertarikan guru pada saat berlangsungnya promosi kesehatan yang menggunakan metode ceramah dan demonstrasi. Dalam berlangsungnya promosi kesehatan, metode dan alat bantu yang dipergunakan dapat membantu untuk lebih memahami isi materi, mempergunakan alat bantu visual dengan menampilkan slide yang berisikan materi promosi kesehatan yang telah diringkas agar mudah dipahami oleh guru. Guru dapat memperoleh pesan atau pengetahuan melalui berbagai macam alat bantu atau media, namun masing-masing alat mempunyai intensitas yang berbeda-beda di dalam membantu pemahaman pesan (Notoatmodjo, 2012)

Hasil wawancara kepada salah satu guru dan penanggung jawab UKS di SMK KAL-1 Surabaya bahwa di SMK KAL-1 belum pernah ada kegiatan atau promosi kesehatan tentang P3Kdi sekolah, sehingga hal ini menjadi dorongan untuk para guru di sekolah untuk memperhatikan materi yang disampaikan. P3Kdi sekolah sendiri sangat penting karena hampir seluruh guru tidak paham bagaimana teknik P3K yang tepat, cepat, dan efisien apabila terjadi kecelakaan kerja saat siswa praktik dengan benda-benda yang berisiiko mencederai.

Menurut (Notoatmodjo, 2012) Perubahan perilaku merupakan proses yang kompleks dan membutuhkan waktu yang relatif lama dan berbeda pada tiap individu. Perubahan perilaku seseorang menerima atau mengadopsi perilaku baru dalam kehidupannya. Apabila penerimaan perilaku baru atau adopsi perilaku melalui proses seperti ini didasari oleh pengetahuan, kesadaran dari sikap yang positif, maka perilaku tersebut akan bersifat langgeng (long lasting). Sebaliknya apabila perilaku itu tidak didasari oleh pengetahuan dan kesadaran maka tidak akan berlangsung lama.

\section{KESIMPULAN}

Hasil penelitian dapat diambil kesimpulan sebagai berikut :

1. Pengetahuan guru tentang P3K pada siswa di SMK KAL-1 Surabaya sebelum diberikan promosi kesehatan sebagian besar kurang.

2. Pengetahuan guru tentang P3K pada siswa di SMK KAL-1 Surabaya setelah diberikan promosi kesehatan sebagian besar baik.

Terdapat peningkatan pengetahuan guru tentang P3K pada siswa di SMK KAL 1 Surabaya setelah diberikan promosi kesehatan.

\section{DAFTAR PUSTAKA}

1. Badan Penelitian dan Pengembangan Kesehatan. (2013a). Laporan Nasional Riset Kesehatan Dasar (RISKESDAS) 2013. In Laporan Nasional 2013 (pp. 1-384). https://doi. org/1 Desember 2013.

2. Badan Penelitian dan Pengembangan Kesehatan. (2013b). Riset Kesehatan Dasar (RISKESDAS) 2013. Laporan Nasional 2013, 1-384. https://doi. org/1 Desember 2013.

3. Gunarsa, S. (2008). Psikologi Perawat. Jakarta: PT BPK Gunung Mulia.

4. Junaidi, I. (2011). Pedoman P3K yang harus dilakukan saat gawat dan darurat medis. Yogyakarta: ANDI.

5. Norman. (2006). Kapita Selekta Kedokteran. Jakarta: Media Aesculapius.

6. Notoatmodjo, S. (2012). Promosi Kesehatan dan Perilaku Kesehatan. Jakarta: Rineka Cipta.

7. Nurhanifah. (2017). Pengaruh Pendidikan Kesehatan Terhadap Tingkat Pengetahuan Pertolongan Pertama Pada Kecelakaan Di 
Sekolah Pada Siswa Kelas VII. Caring Nursing Jurnal.

8. Rizqiani. (2016). Pengaruh Pendidikan Kesehatan First Aid Box Terhadap Tingkat Pengetahuan Orang Tua Dalam Penanganan Cedera Anak Toddler Di Rumah Tangga. Universitas Muhammadiyah Yogyakarta.

9. Thygerson, A. (2011). P3K Edisi Kelima. Jakarta: Erlangga.

10. Wawan, A., and Dewi, M. (2011). Teori \& Pengukuran pengetahuan Sikap Perilaku Manusia. Yogyakarta: Nuha Medika.

11. Yuda, H., Tamara, and Agina, P. (2015). Pengetahuan Tentang Penanganan Kegawatdaruratan Pada Siswa Anggota Hizbul Wathan Di SMA Muhammadiyah Gombong. Ilmu Kesehatan Keperawatan, 11(3). 